\title{
Evaluation of volatile constituents profile in Scotch whisky by SPME/GC-IT MS
}

Câmara, J.S. ${ }^{*}$, Marques, J.C.; Perestrelo, R.M.; Rodrigues, F.; Oliveira, L.; Andrade, P.;. Caldeira, $M$.

Centro de Química da Madeira, Departamento de Química, Universidade da Madeira, Campus Universitário da Penteada, 9000-390 Funchal, Portugal.

E-mail.: jsc@uma.pt (José S. Câmara)

\begin{abstract}
A dynamic headspace solid-phase microextraction (HS-SPME) and gas chromatography coupled to ion trap mass spectrometry $\left(\mathrm{GC}-{ }_{-\mathrm{IT}} \mathrm{MS}\right)$ method was developed and applied for the qualitative determination of the volatile compounds present in commercial whisky samples which alcoholic content was previously adjusted to $13 \%(\mathrm{v} / \mathrm{v})$. Headspace SPME experimental conditions, such as fibre coating, extraction temperature and extraction time, were optimized in order to improve the extraction process. Five different SPME fibers were used in this study, namely, poly(dimethylsiloxane) (PDMS), poly(acrylate) (PA), Carboxenpoly(dimethylsiloxane) (CAR/PDMS), Carbowax-divinylbenzene (CW/DVB) and Carboxenpoly(dimethylsiloxane)-divinylbenzene (CAR/PDMS/DVB) The best results were obtained using a $75 \mu \mathrm{m} C A R / P D M S$ fibre during headspace extraction at $40^{\circ} \mathrm{C}$ with stirring at $750 \mathrm{rpm}$ for $60 \mathrm{~min}$, after saturating the samples with salt. The optimised methodology was then applied to investigate the volatile composition profile of three Scotch whiskeys - Black Label, Ballantines and Highland Clan. Approximately seventy volatile compounds were identified in the these samples, pertaining at several chemical groups, mainly fatty acids ethyl esters, higher alcohols, fatty acids, carbonyl compounds, monoterpenols, $\mathrm{C}_{13}$ norisoprenoids and some volatile phenols. The ethyl esters form an essential group of aroma components in whisky, to which they confer a pleasant aroma, with "fruity" odours. Qualitatively, the isoamyl acetate, with "banana" aroma, was the most interesting. Quantitatively, significant components are ethyl esters of caprilic, capric and lauric acids. The highest concentration of fatty acids, were observed for caprilic and capric acids. From the higher alcohols the fusel oils (3-methylbutan-1-ol and 2-phenyletanol) are the most important ones.
\end{abstract}

Keywords: Whisky analysis, headspace-solid phase microextraction (HS-SPME), Volatile compounds, Gas Chromatography-Mass spectrometry (GC-MS)

\section{Introduction}

Whisky samples contain a great variety of flavour compounds belonging to different chemical families such as: higher alcohols, ethyl and isoamyl esters, acetates, fatty acids, ketones, monoteropenes, $\mathrm{C}_{13}$ norisoprenoids and phenols. These compounds can be present in a wide range of concentrations (from ng/l to several $\mathrm{g} / \mathrm{l}$ ) and vary widely in volatility and polarity which consequently affects their extraction and chromatographic profile. Some of these originate from the raw materials and the subsequent processes of mashing, fermentation, distillation and ageing, while others are oak derived. Many of these compounds are common to different whiskies but differ

The application of SPME to different areas in analytical chemistry has been steadily increasing. In recent years, this methodology has been widely adopted in many fields including pharmaceutical, clinical, forensic, food, environmental, physicochemical and 
flavour, fragence and pheromone applications. This technique has been successfully applied in wine samples (Garcia et al., 1999; Garcia et al., 1998) to characterise a wide range of aroma compounds, including monoterpenes and $C_{13}$ norisoprenoids (Câmara et al. 2004), esters (Rodriguez-Bencomo et al. 2002), volatile and low volatile sulphides and disulphides (Mestres et al. 2000; Mestres et al. 1999), oak lactones in barrel aged wines (Pollnitz et al. 1999), organochlorine insecticides in Portuguese red and white wines (Correia M. et al. 2000) and 3-alkyl-2-methoxypyrazines in Cabernet-Sauvignon and Merlot wines (Sala et al. 2002).

More recently, Câmara et al (2006a) studied the opimization of headspace SPME for the analysis of wine aroma compounds, in which the influence of various parameters, such as sampling time, temperature and alcohol content, on the extraction efficiency of terpenoids was investigated. Rocha et al. (2006) decribes a novel methodology for the rapid distinction in wines based on the global volatile signature obtained by HS-SPME coupled to gas chromatography-mass spectrometry followed by principal component analysis of the data. The free and pre-fermentative related volatile compounds, mainly monoteroenoids, norisoprenoids, aromatic alcohols, as well as, sesquiterpenoids that arise after crushing the grapes were followed by HS-SPME (Coelho et al. 2006).

Although the SPME analysis of volatiles and semi-volatiles in a wide range of matrices has been described, to date very few papers are available to the analysis of whiskeys volatiles. In this study a HS-SPME-GC-ITMS method for the analysis, identification and evaluation, of the volatile constituents in Scotch whisky samples is proposed. Three SPME parameters with influence in the extraction process were selected for optimisation: fibre coating, extraction time and extraction temperature. A comparison between five SPME different fibres is made.

\section{Experimental}

\section{Samples}

Commercial Scotch whisky samples (40\%, v/v, alcohol), Black Label (BL), Ballantines (Bal) and Highland Clan (HC), were purchased from a local store (Funchal, Madeira Island), and frozen at $-28{ }^{\circ} \mathrm{C}$ until their analysis. Before extraction the volatile compounds, the samples were unfrozen at $3-4{ }^{\circ} \mathrm{C}$. All samples were adjusted to $13 \%(\mathrm{v} / \mathrm{v})$ alcohol by dilution with distilled water prior extraction.

\section{Optimization of HS-SPME procedure}

HS-SPME is an equilibrium technique that requires a previous optimization of the extraction parameters that can affect extraction efficiencies, in order to obtain high recoveries of volatiles. Some of these sampling conditions are fiber sorbent (absorvent/adsorvent) phase, extraction temperature and extraction time.

\section{Dynamic HS-SPME of volatile compounds}

Three SPME parameters with influence in the extraction process were selected for optimisation: fibre coating, extraction time and extraction temperature. The methodology developed by Câmara et al. (2006a, 2006b) for the volatile compounds extraction using HSSPME was used with minor modifications.

An equilibration study was performed (5, 15, 3045 and $60 \mathrm{~min}$.) to determine the most suitable extraction time for whisky volatiles. The high ethanol concentration $(40 \%, \mathrm{v} / \mathrm{v})$ of the whiskeys required sample dilution. After adjust to $13 \%(\mathrm{v} / \mathrm{v})$ alcohol by dilution with distilled water, whisky samples were adjusted to $\mathrm{pH} 3.3$ and the ionic strength was increased to improve the extraction efficiency using $\mathrm{NaCl}(30 \%)$. A $60 \mathrm{ml}$ vial containing $35 \mathrm{ml}$ of sample, spiked with $0.422 \mu \mathrm{g} / 1$ of octan-3-ol (Sigma-Aldrich), which was used as internal standard $(50 \mu \mathrm{l}$ of alcoholic solution at $422 \mathrm{mg} / \mathrm{l})$, was placed in a thermostatic block on a stirrer. The fibre was then exposed to the gaseous phase for an appropriate time period at 
temperature of $30 \pm 1{ }^{\circ} \mathrm{C}$. As stirring usually improves the extraction, because the static layer resistant to mass transfer is destroyed (facilitate mass transport between the bulk of the aqueous sample and the fibre), all the experiments were performed under constant stirring velocity $(750 \mathrm{rpm})$. After extraction, the SPME fibre was withdrawn into the needle, removed from the vial and inserted into the hot injector port $\left(240^{\circ} \mathrm{C}\right)$ of the GC-MS system for 6 min. where the extracted chemicals were desorbed thermally and transferred directly to the analytical column.

\section{Analysis of volatile compounds by GC-MS}

The whisky extracts were analyzed by GC-MS using a Varian STAR 3400Cx series II gas chromatograph, equipped with a $30 \mathrm{~m} \times 0.5 \mathrm{~mm}$ I.D., with a $0.25 \mu \mathrm{m}$ film thickness, DBWaxter fused silica capillary column, connected to a Varian Saturn III mass selective detector, according to the method described by Câmara et al [10]. Splitless injections were used. The initial oven temperature was set to $40^{\circ} \mathrm{C}$ (for $1 \mathrm{~min}$ ), then increased in three steps: 40 to $120 \mathrm{C}$, at $1^{\circ} \mathrm{C} / \mathrm{min} ; 120$ to $180 \mathrm{C}$ at $1.7^{\circ} \mathrm{C} / \mathrm{min}$ and 180 to $220^{\circ} \mathrm{C}$, at $25^{\circ} \mathrm{C} / \mathrm{min}$. Each step was preceded by a small period at constant temperature for $2 \mathrm{~min}, 1 \mathrm{~min}$ and $10 \mathrm{~min}$, respectively. The injector temperature was $260^{\circ} \mathrm{C}$ and the transfer line was held at $220^{\circ} \mathrm{C}$. The carrier gas was Helium N60 (Air Liquid, Portugal) with a column-head pressure of 13 psi (1 psi $=6894.76 \mathrm{~Pa}$ ). The detection was performed by a Saturn III mass spectrometer in the electronic impact (EI) mode (ionization energy, $70 \mathrm{eV}$; source temperature, $180^{\circ} \mathrm{C}$ ). The electron multiplier was set to the auto tune procedure. The acquisition was made in full scan

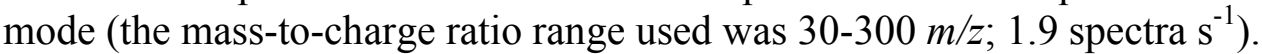

\section{Results and discussion}

\section{Selection of SPME fibre coating}

To investigate the extraction yields of the whisky volatiles components, five fibre coatings: PDMS, PA, DVB/CAR/PDMS, CW/DVB and CAR/PDMS, were checked. To select the best coating the headspace extraction of whisky volatile constituents was carried out using an temperature of $40^{\circ} \mathrm{C}$ for $60 \mathrm{~min}$, after saturating the samples with $\mathrm{NaCl}$.

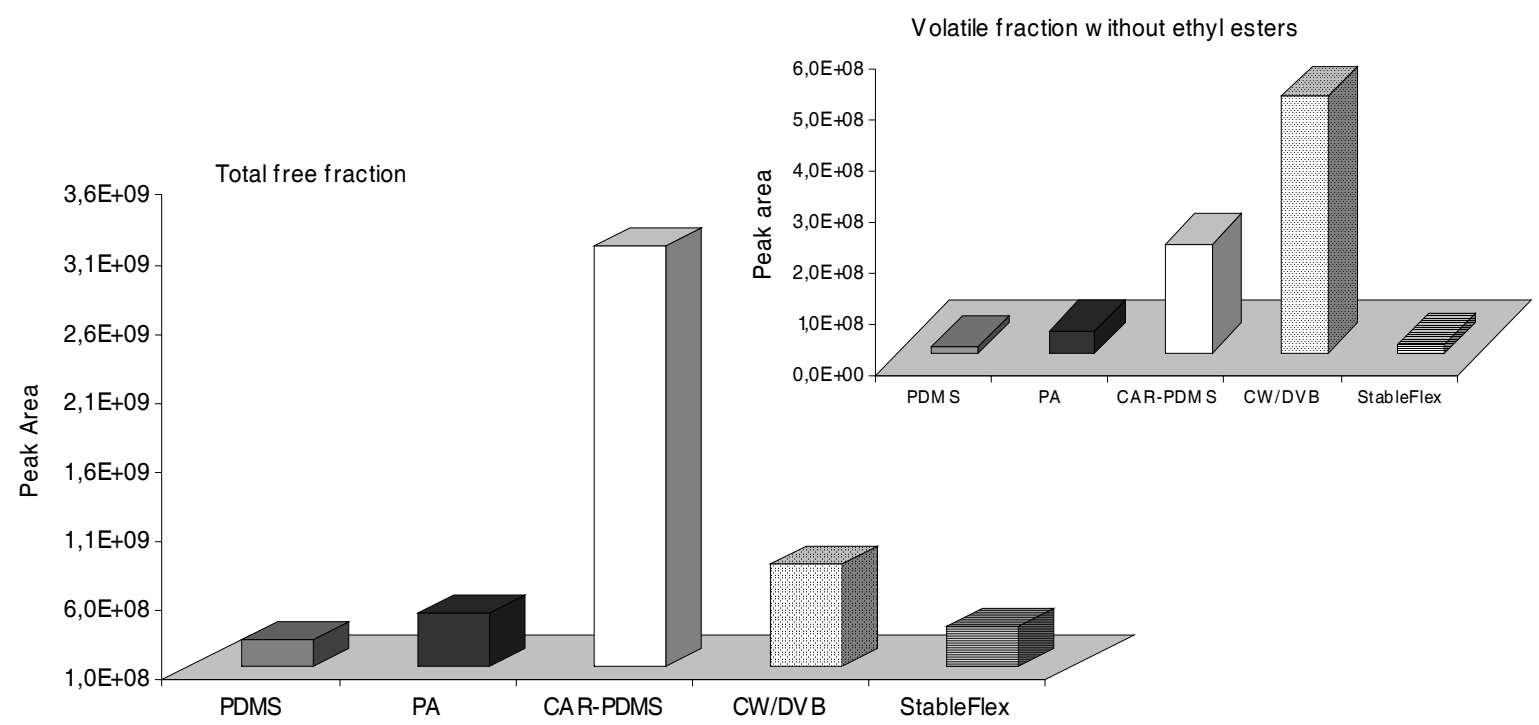

Fig. 1. Influence of the type of HS-SPME fibre coatings on the GC-MS peak area for the total fraction of the volatile compounds in BL whiskey sample, using an extraction temperature of $30{ }^{\circ} \mathrm{C}$ and an extraction time of $60 \mathrm{~min}$. 
For reasons of comparability all tests were carried out with the same whisky sample (Black Label). The peak areas of the total free fraction present in the Black Label whisky were used for the evaluation of the optimal fibre. The results were shown in Fig. 1., indicating that the $75 \mu \mathrm{m}$ CAR/PDMS fibre provided the highest extraction efficiency for the volatiles. Therefore this fiber was chosen for the remaining studies: extraction temperature, extraction time and whisky volatiles.

\section{Effect of extraction temperature}

The influence of the extraction temperature was investigated by sampling a BL whisky at different temperatures $-25,40,50$ and $60{ }^{\circ} \mathrm{C}$, with a constant extraction time of $60 \mathrm{~min}$. The results are summarised in table 1 . As can be observed an increase in extraction temperature generally improves the mobility of volatile compounds through liquid and gas phases and better extraction efficiencies were obtained.

Table 1

Influence of the extraction temperature on adsorption of different BL whisky volatile compounds, classified according to functional group, during dynamic headspace SPME extraction using a $75 \mu \mathrm{m}$ CAR/PDMS fibre (extraction of salt saturated sample $-30 \%(\mathrm{w} / \mathrm{v})$ $\mathrm{NaCl}$ at $40^{\circ} \mathrm{C}$, for $60 \mathrm{~min}$.), expressed as peak area $(n=3)$

\begin{tabular}{lcccc}
\hline \multirow{2}{*}{ Class of compounds } & \multicolumn{4}{c}{ Extraction temperature $\left({ }^{\boldsymbol{O}} \boldsymbol{C}\right)$} \\
\cline { 2 - 5 } & $\mathbf{2 5}$ & $\mathbf{4 0}$ & $\mathbf{5 0}$ & $\mathbf{6 0}$ \\
\hline \hline Terpenes/Norisoprenoids & $5.74 \mathrm{E}+06$ & $7.58 \mathrm{E}+06$ & $4.15 \mathrm{E}+06$ & $4.59 \mathrm{E}+06$ \\
Higher alcohols & $2.89 \mathrm{E}+07$ & $2.48 \mathrm{E}+08$ & $3.05 \mathrm{E}+08$ & $4.63 \mathrm{E}+08$ \\
Acetates & $2.15 \mathrm{E}+07$ & $3.09 \mathrm{E}+07$ & $1.87 \mathrm{E}+07$ & $1.78 \mathrm{E}+07$ \\
Isoamyl esters & $9.14 \mathrm{E}+06$ & $1.10 \mathrm{E}+07$ & $1.25 \mathrm{E}+07$ & $1.27 \mathrm{E}+07$ \\
Ethyl esters & $5.23 \mathrm{E}+07$ & $5.71 \mathrm{E}+07$ & $5.78 \mathrm{E}+07$ & $6.05 \mathrm{E}+07$ \\
Fatty acids & $2.78 \mathrm{E}+07$ & $5.41 \mathrm{E}+07$ & $2.28 \mathrm{E}+07$ & $7.90 \mathrm{E}+07$ \\
Carbonyl compounds & $9.14 \mathrm{E}+05$ & $4.14 \mathrm{E}+05$ & $4.12 \mathrm{E}+05$ & $3.14 \mathrm{E}+05$ \\
Phenols & $6.08 \mathrm{E}+05$ & $6.65 \mathrm{E}+05$ & $4.72 \mathrm{E}+05$ & $4.35 \mathrm{E}+05$ \\
Miscellaneous & $9.25 \mathrm{E}+06$ & $7.17 \mathrm{E}+06$ & $9.54 \mathrm{E}+06$ & $6.24 \mathrm{E}+06$ \\
\hline \hline
\end{tabular}

\section{Effect of extraction time}

A graph of the MS response against the SPME sampling period, for CAR/PDMS fibre desorption after different extraction times (5-60 min), for the chemical groups considered in this study, is displayed in Fig. 2.

It is observed hat a typical extraction profile consist of an initial rapid portioning followed by a slower prolonged uptake and finally a steady-state equilibrium between the fibre and the vapour phase of the analyte.

It is also apparent that the extraction time profile depends on the chemical group, but in particular on the polymeric phase 

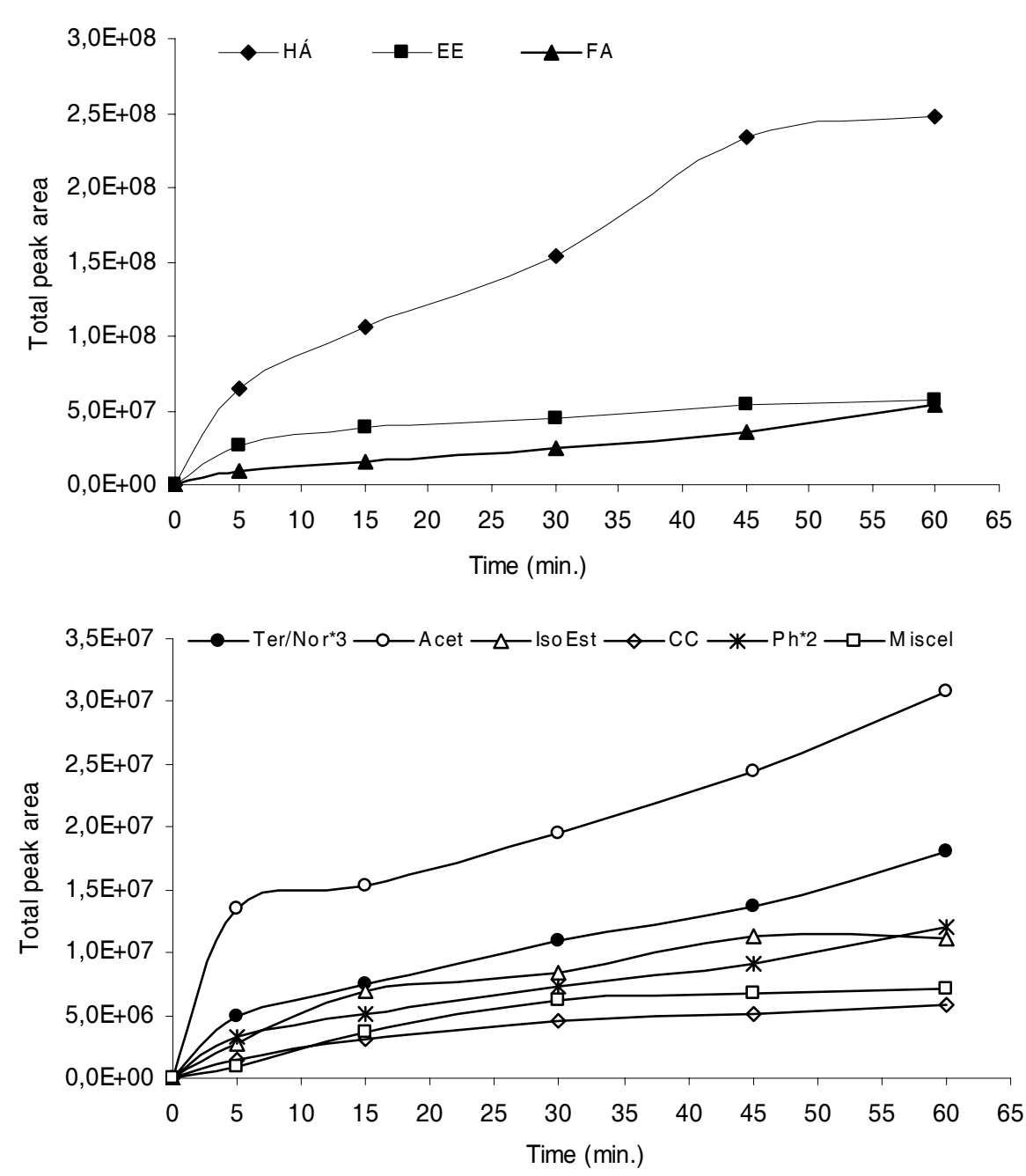

Fig. 2. Influence of the sampling time on the extraction efficiency for whisky volatile compounds, during dynamic headspace SPME extraction using a $75 \mathrm{~m}$ CAR/PDMS fibre (extraction of salt saturated sample $-30 \%(\mathrm{w} / \mathrm{v}) \mathrm{NaCl}$ at $40{ }^{\circ} \mathrm{C}$ ), expressed as peak area.

Study of the volatile compounds in BL, Bal, and HC whiskeys

After optimisation the experimental parameters with influence in the extraction process, the volatile constituents present in the headspace of BL, Ball and $\mathrm{HC}$ whiskeys were analysed. A typical total ion chromatogram obtained from studied whisky samples using the experimental conditions discussed above are shown in Fig. 3.

More than seventy compounds were identified in BL and sixty in Ball and HC wkhiskeys, including ethyl esters, higher alcohols, acetates, isoamyl esters, fatty acids, terpenes $/ \mathrm{C}_{13}$ norisoprenoids, carbonyl compounds and phenols. The differences observed according to the whisky sample were mainly quantitative.

Quantitatively, the ethyl esters are the largest group of the studied whisky volatile constituents: $72.1 \%$ in Ball, $68.5 \%$ in $\mathrm{HC}$ and $59.5 \%$ in BL. The ethyl esters from C8, C10 and $\mathrm{C} 12$ fatty acids, which contributed with sweet and fruity notes, and isoamyl alcohols, represent the major compounds in either of the analysed whiskeys. The relative amount of ethyl esters in the different types of studied wihiskys was reasonably constant and the differences were not significant. From the ethyl esters of diprotic acids, the relative amount of 
diethyl succinate is much higher than that found for ethyl lactate. Similar contents of diethyl succinate were observed in all the analyzed whiskeys(Fig. 4.).

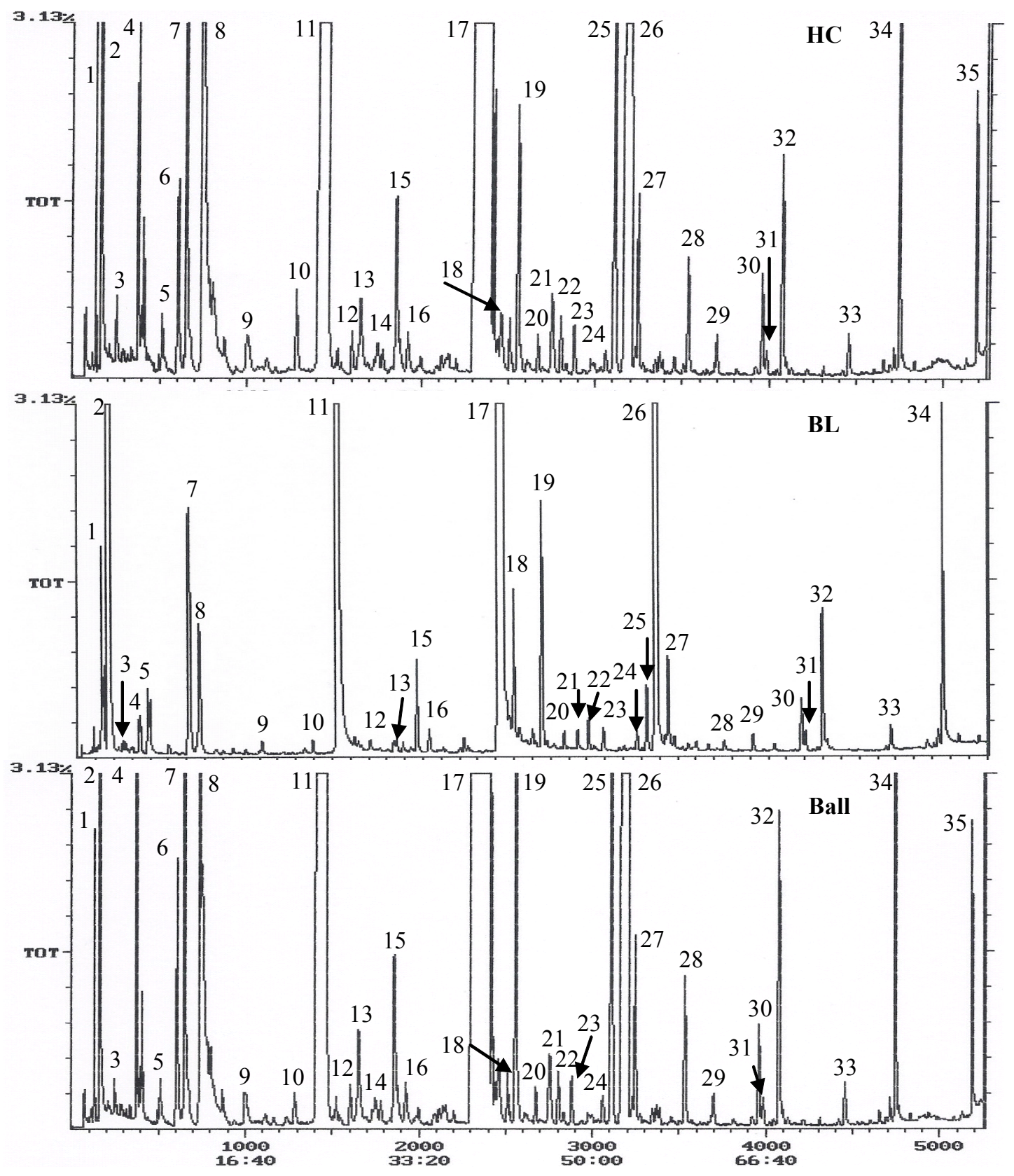

Fig. 3. Typical total ion chromatogram of volatile constituents from $\mathrm{HC}, \mathrm{BL}$ and Ball whiskeys samples obtained by SPME using a CAR/PDMS coating in the headspace sampling mode. Extraction conditions: extraction temperature: $40^{\circ} \mathrm{C}$; extraction time: $60 \mathrm{~min}$; stirring: $750 \mathrm{rpm}$; sample volume: $30 \mathrm{ml}$; headspace volume: $30 \mathrm{ml}$; desorption was performed at $220^{\circ} \mathrm{C}$ for $6 \mathrm{~min}$.

Peak Identification: 1: ethyl acetate; 2: ethanol; 3: butan-1-ol; 4: isoamyl acetate; 5: 4-methylpentan-2-ol (IS); 6: 3-methylbutan-1ol; 7: ethyl hexanoate; 8: estirene; 9: ethyl heptanoate; 10: octan-3-ol (IS); 11: ethyl decanoate; 12: 1,15-pentadecanediol; 13: furfural; 14: VitisI+VitisII; 15: propyl octanoate; 16: butyl caprylate; 17: isoamyl octanoate; 18: cyclodecanemethanol; 19: ethyl 9-decanoate; 20: propyl decanoate; 21: azulene; 22: buthyl decanoate; 23: dodecan-1-ol; 24: -Damascenone; 25: 2-phenylethanol acetate; 26: ethyl decanoate; 27: isoamyl decanoate; 28: phenylethanol; 29: 1,14-tetradecanediol; 30: ethyltetradecanoate; 31: nerolidol; 32: octanoic acid; 33: 1,12 dodecanediol; 34: decanoic acid; 35: dodecanoic acid. 
Isoamyl acetate with a characteristic odour of "banana", was found at similar values in different studied whiskeys. The content of 2-phenylethyl acetate determined in Ball, which give "roses, flowery, honey" nuances to the whisky, was significantly different at the $95 \%$ level, from the determined for BL and $\mathrm{HC}$ whiskeys

Higher alcohols fraction is composed mainly by $n$-alcohols of $\mathrm{C}_{6}$ chain length and aromatic compounds such as 2-phenylethanol. The presence of these compounds may cause a "flowery" and "sweet" notes which could be considered as a positive characteristic for whiskeys. 3-Methylbutan-1-ol and 2-phenylethanol were markedly the most abundant higher alcohols in BL whisky, with an RPA of 17.6 for the first and 6.9 for the second. The contents of isoamyl alcohol were notably higher in the BL whisky (17.6) contrary to HC (4.5) that present the lowest content.

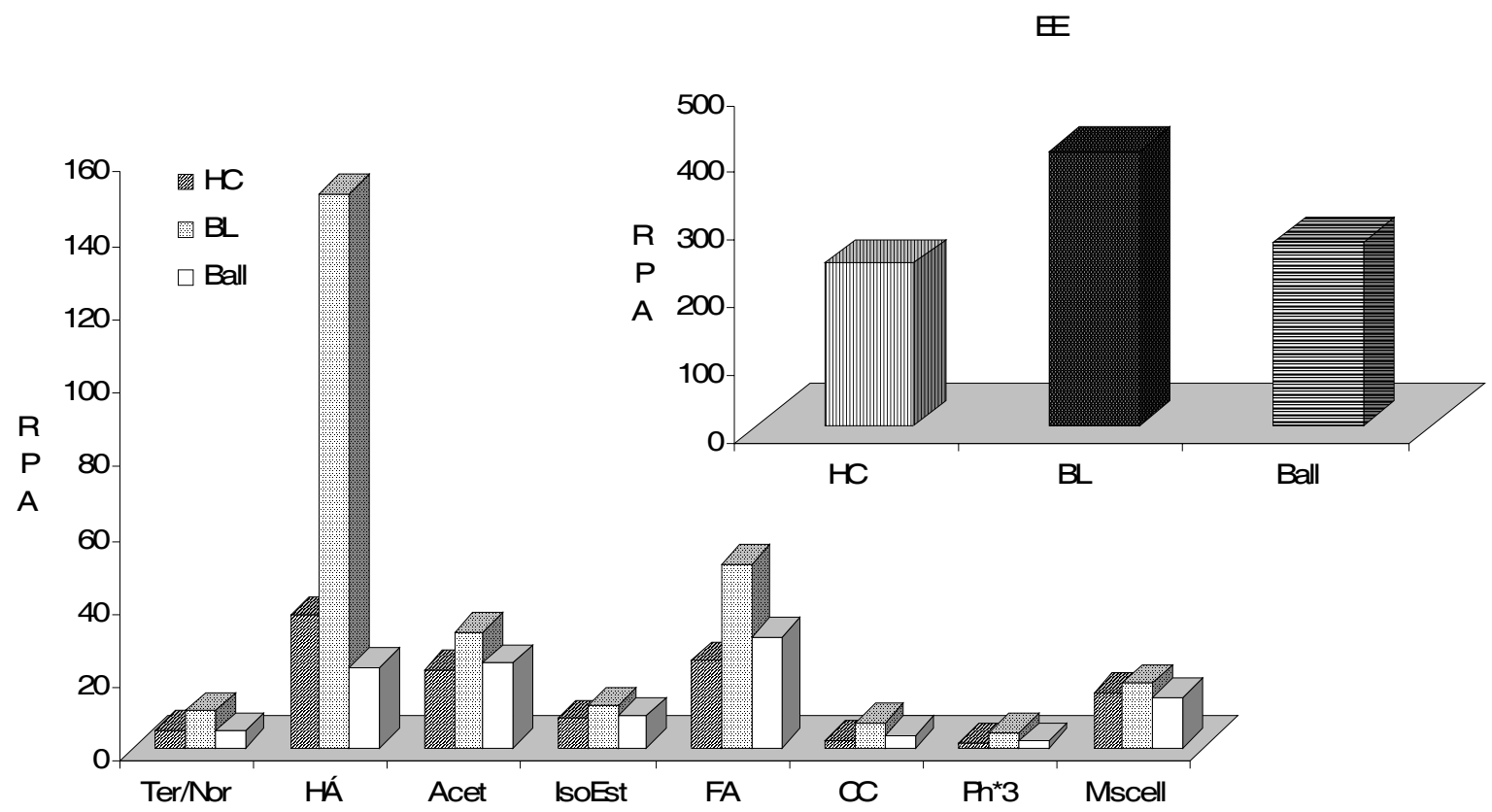

Fig. 4. Relative composition of the whiskeys - hidrocarbons, monoterpenols, norisoprenoids, higher alcohols, ethyl esters, acetates, fatty acids, carbonylated and miscelaneous compounds

The most important fatty acids present in the whisky samples studied were $\mathrm{C} 8, \mathrm{C} 10$ and $\mathrm{C} 12$. Fatty acids content in the analysed whiskeys, not differ significantly at the $95 \%$ level: $8.0 \%$ for Ball, $7.3 \%$ for BL, and $6.7 \%$ for HC samples. Only few aldehydes have been detected among the whisky volatile constituents, probably because they can be reduced to the corresponding alcohols. The carbonyl compounds content in Ball $(\mathrm{RPA}=3.4)$ and $\mathrm{HC}$ $(\mathrm{RPA}=2.0)$ whiskeys is similar but in $\mathrm{BL}$ samples this values is much higher $(\mathrm{RPA}=6.8)$. Terpenoids, which may have an important contribution on the "floral" and "fruity" aromas of the whiskeys, and $\mathrm{C}_{13}$ norisoprenoids (derived from carotenoids degradation) that contributed with "camphor", "honey-like" or "cassis" notes, are most abundant in BL samples. Contrarly the lowest level of these compounds are found in Ball whiskeys samples. The three analysed whiskeys have in common the trans- $\beta$-damascenone, 1,2-dihydro-1,1,6-trimethylnaphthalene and the two vitispirane isomers.

Quantitatively, ethyl esters (mainly ethyl octanoate, ethyl decanoate and ethyl dodecanoate) are the largest group of the volatile composition found in studied whiskeys. The higher alcohols (aliphatic and aromatic) and fatty acids constitute important groups of aroma 
compounds that contribute with "fruity" and "cheese/fatty" notes to whisky sensory properties. The dominating esters are the ethyl esters of fatty acids and acetates of higher alcohols. Ethyl octanoate and ethyl hexanoate predominated in TNM red wines analysed.

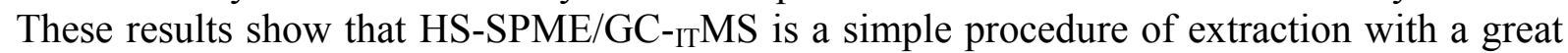
capacity of concentration and combines extraction and concentration in one step, rapid, sensitive and solvent-free method suitable for determination of volatiles and semivolatiles constituents in whisky.

\section{References}

Câmara, J.S.; Alves, M.A; Marques, J.C. 2006a. Anal. Chimica Acta 555, 191.

Câmara, J.S.; Alves, M.A; Marques, J.C. 2006b. Talanta 68, 1512.

Câmara, J.S.; Herbert, P.; Marques, J.C.; Alves, M.A 2004. Anal. Chimica Acta, 513, 203.

Coelho, E.; Rocha, S.M.; Delgadillo, I.; Coimbra, M.A. 2006. Anal. Chimica Acta 563, 204.

Correia, M.; Delerue-Matos, C.; Alves, JM.A. 2000. J. Chromatogr. A 889, 59.

Garcia, D. De la Calle; Magnaghi, S.; Reichenbacher, M.; Danzer, K. 1998. Vitis, 37,181.

Garcia, D. De la Calle; Reichenbacher, M.; Danzer, K.; Bartzch, C.; Feller, K. 1999. J. High Resolut. Chromatogr. 22(6), 322.

Mestres, M.; Marti, M.P.; Busto, O.; Guasch, J. 2000. J. Chromatogr. A 881, 583.

Mestres, M.; Sala, C.; Busto, O.; Guasch, J. 1999. J. Chromatogr. A 835, 137.

Pollnitz, A.P.; Jones, G.P.; Sefton,M.A. 1999. J. Chromatogr. A 857, 239.

Rocha, S.M.; Coutinho, P.; Barros, A.; Delgadillo, I.; Coimbra, M.A. 2006. J. Chromatogr. A $1114,188$.

Rodriguez-Bencomo, J.J.; Conde, J.E.; Rodriguez-Delgado, M.A.; Garcia-Montelongo, F.; Pérez-trujillo, J.P. 2002. J. Chromatogr. A 963, 213.

Sala, C.; Mestres, M.; Marti, M.P.; Busto, O.; Guasch, J. 2002. J. Chromatogr. A 953, 41. 